\title{
Ecology of Heterotrophic Microflagellates. III. Adaptations to Heterogeneous Environments
}

\author{
T. Fenchel \\ Department of Ecology and Genetics, University of Aarhus, Ny Munkegade, DK-8000 Aarhus C, Denmark
}

\begin{abstract}
The response to starvation and to feeding after a period of starvation was studied in heterotrophic microflagellates. Starvation immediately leads to a decrease in metabolic rate which eventually falls to 2 to $5 \%$ of that characteristic for growing cells and to autophagy of cell organelles, in particular mitochondria. At the onset of starvation, the studied species undergo one or two additional divisions leading to small, more lively cells. When starving cells are fed, they immediately take up food and increase their $\mathrm{O}_{2}$-uptake; the time lag after which cell division and a metabolic rate characteristic of growth occur increases with starvation time. These properties are discussed in terms of adaptation to temporally heterogeneous environments, and it is pointed out that the behavior found must be a compromise between the ability to survive and to resume cell divisions rapidly when food is again available. The absence of cysts in the studied forms is discussed and it is suggested that the techniques employed for obtaining clonal cultures select against cyst-forming species or clonal lines.
\end{abstract}

\section{INTRODUCTION}

Ecological bioenergetics of protists has so far concentrated on the measurement of parameters of balanced growth (e.g. Curds and Cockburn, 1968, 1971; Hamilton and Preslan, 1970; Laybourn and Finlay, 1976; Fenchel, 1982b) and the results have been projected back to nature (e.g. Finlay, 1978). However, microorganisms do not live in a constant environment. Already the fact that protozoans studied in the laboratory may show growth rate constants which vary over a range of a factor of 10 or more according to environmental factors (e.g. Curds and Cockburn, 1971; Fenchel, 1982b) suggests that this range is also realized in nature at different times. This is because changes in growth rate imply profound changes in cellular physiology (regulation of synthesis of RNA and protein, regulation of metabolic rate), and the ability to change division rate must be considered as an adaptation to heterogeneous environments (Koch, 1971). Furthermore, resources may periodically fall below a level which allows any growth. For example, bacterivorous protozoans will grow rapidly in a patch with decaying organic material. After some time, however, the completed mineralization of the material in conjunction with high population densities of protozoans will lead to an intense competition for food bacteria and eventually starvation. Even a seemingly homogeneous natural environment, such as the marine pelagial, is patchy in time and space on all scales (Haury et al., 1978). Clearly, the scale of heterogeneity of interest to a protozoan with a potential generation time of a few hours is different from the scale of interest to an animal with a generation time of a year. There is evidence of patchiness in the sea at a scale of interest to Protozoa. Meyer-Reil et al. (1979) demonstrated daily fluctuations in bacterial numbers in the Baltic Sea and Fenchel (1982c) demonstrated cyclical changes in bacterial numbers of the order of weeks. In terms of spatial heterogeneity, suspended decaying remains of plankton organisms may represent patchiness to be measured in $\mathrm{cm}$ or $\mathrm{m}_{\text {; }}$ for protozoans with swimming speeds of around $100 \mu \mathrm{m} \mathrm{s}^{-1}$ this may represent temporal patchiness of a scale not too different from their generation times. In short, Protozoa may experience nature less like a chemostat than as an existence of 'feast and famine' in the sense of Koch (1971).

The present paper is one in a series (Fenchel, 1982a, $\mathrm{b}, \mathrm{c})$ treating the biology and ecology of planktonic, bacterivorous microflagellates. In this context, the responses and adaptations to starvation and to the reappearance of food will be described here. 


\section{MATERIALS AND METHODS}

The species used in this study, as well as isolation and maintenance techniques and bioenergetics of balanced growth are described in Fenchel (1982a, b). In the present study observations on the choanoflagellate Monosiga sp., the bicoecid Pseudobodo tremulans Griessmann and the kinetoplastid Pleuromonas jaculans Perty are included. Most experimental data, however, derive from the chrysomonad Ochromonas sp.

Starving cells were, in all cases, obtained from batch cultures in which all bacterial food had been consumed. This implies that the initiation of starvation and the end of growth is not very exactly defined. However, the dynamics of the cultures is such that after many generations of exponential growth, during which food resources decrease slowly, the eventually large flagellate population will deplete the food resources entirely within 1 to 2 generations. This gives a reasonably well defined zero time for starvation experiments (Fenchel, 1982b). Counts of cells and respiratory rates were measured as in Fenchel (1982b). All experimental data refer to $20^{\circ} \mathrm{C}$ and darkness, unless otherwise stated. Cell volumes were determined as spheres from the diameter of formaldehyde-fixed cells. It was later found that in Ochromonas sp. this method of fixation sometimes leads to a swelling of the cells relative to live ones and the volumes given in Figs. 2, 4 and 6 are systematically too large. Since it was not possible afterwards to estimate the exact amount of swelling in the particular experiments the data have not been corrected, but live volumes are roughly 2 times lower than indicated in the mentioned figures (corresponding to a linear swelling of $\times 1.25$ ).

Transmission electron microscopical work was carried out as described in Fenchel (1982a). For the quantification of changes in organelle sizes and numbers, methods of stereology were used. For a thorough geometrical and statistical treatment of these methods, see Hennig (1967), Weibel and Elias (1967) and Elias et al. (1968). For each sample, at least 20 TEM sections of individual cells (magnification: 20,000 $\times$ ) were used. For planimetry, a transparent point grid (grid length: $0.5 \mathrm{~cm}$ ) was placed over the photographs to determine area fractions. For measuring line interceptions a similar technique was employed. From such data, volume fraction of organelles and internal surface per unit volume can easily be calculated since the former is identical to area fraction and the latter to number of intersections per unit length. For the estimation of numbers of mitochondria per unit volume, $N$, the equation $N=n / A \bar{D}$ was employed, where $n=$ number of organelles seen in a section; $\bar{D}=$ mean caliper diameter of the organelle; $A=$ area. The thickness of the sections is assumed to be zero (which may be permis- sible because it is small relative to the organelles of interest) and 'overlooked caps' in the sections were ignored because there was no way to estimate them. These simplifications may lead to a slight underestimate of mitochondrial numbers. It was found, that when dividing mitochondria were excluded from the analysis, the statistical distribution of the ratios of the short and the long axis of the sections closely fitted to that expected for randomly cut cylinders (Elias et al. 1968). With the assumption of cylindrical shape, the diameter of the mitochondria could be estimated from the short axis of the sections and the length from the distribution of the ratios; the mean caliper diameter is then given as $\bar{D}=(1+\pi r) / 2$ where 1 and $r$ are length and radius, respectively. The estimate of the dimensions of individual mitochondria allowed for a calculation of total mitochondrial volume completely independent from that derived from measurements of area fractions. The two estimates are in reasonable agreement (Fig. 9).

\section{RESULTS}

\section{Post-Feeding Cell Divisions}

In all studied species, the cells undergo on average 1 (e.g. Ochromonas sp.) or 2 (Monosigasp., Pseudobodo tremulans) divisions after food has become nearly depleted in the cultures. Consequently, cells with volumes 2 , respectively 4 times smaller than those of growing cells appear (Fig. 2; see also Fenchel, 1982b). In Monosiga sp. and in $P$. tremulans morphologically and behaviourly differentiated swarmers result from these terminal divisions. They are more slender and swim constantly in constrast to trophic cells which tend to attach themselves to some substrate. In Monosiga sp. (but not in $P$. tremulans) swarmers occur as a small

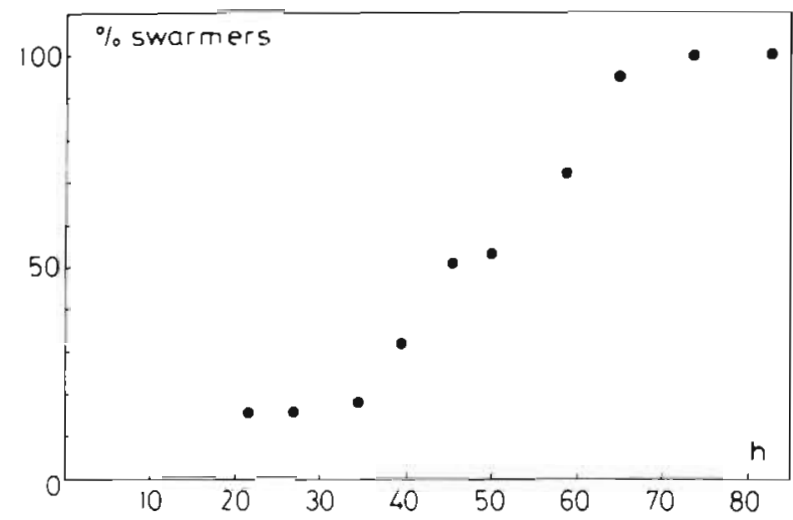

Fig. 1. Monosiga sp. Percentage of swarmers in a batch culture of this choanoflagellate. Balanced exponential growth took place until about $35 \mathrm{~h}_{\mathrm{i}}$ at $55 \mathrm{~h}$ food bacteria were nearly completely depleted 
fraction of the individuals throughout the growth phase of cultures, but when food is eventually depleted, swarmers make up $100 \%$ of the population (Fig. 1). Cyst formation never occurred as a response to starvation (or otherwise) in any of the clonal cultures studied.

\section{Survival and Respiratory Rate during Starvation}

In Ochromonas sp. nearly no mortality took place until some 60 to $80 \mathrm{~h}$ after initiation of starvation; thereafter, cell numbers decreased roughly exponentially with a half-life of some $20 \mathrm{~h}$. Cell volume decreased by a factor of 2 as a result of the last cell division, thereafter only at a slow rate (Figs. 2, 4, and 6).

During exponential growth, $\mathrm{O}_{2}$-uptake is nearly proportional to the growth rate constant and for rapidly growing Ochromonas sp. it is about $4 \times 10^{-9} \mathrm{mg} \mathrm{O}_{2}$ cell $^{-1} \mathrm{~h}^{-1}$ (Fenchel, 1982b). At the onset of the last division in a batch cultures it begins to decrease and then falls fairly rapidly to about $10 \%$ of the growth value. After some $20 \mathrm{~h}$ the rate of decrease levels off and after $100 \mathrm{~h}$ of starvation $\mathrm{O}_{2}$-uptake is $2-5 \%$ of the growth level (Fig. 2). The respiratory rate of the kineto-

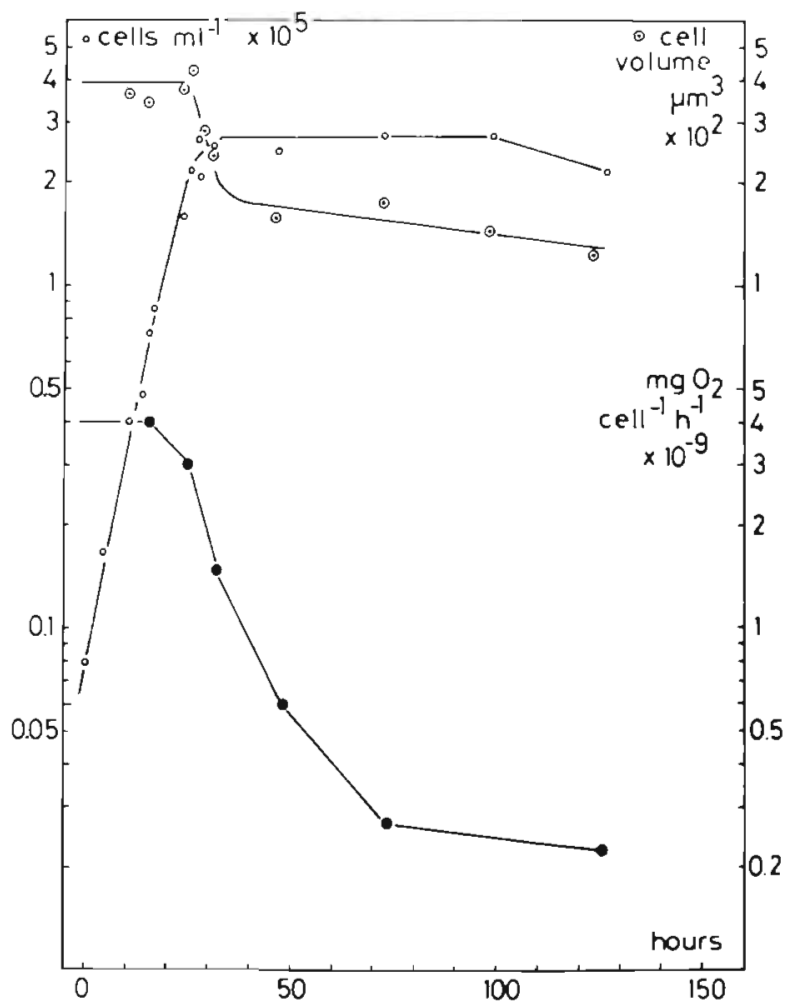

Fig. 2. Ochromonas sp. Batch culture initiated with $2 \times 10^{8}$ food bacteria $\mathrm{ml}^{-1}$ showing cell numbers, volume and respiratory rate per cell plastid flagellate Pleuromonas jaculans behaved quite similarly to that of Ochromonas sp. during starvation.

\section{Responses of Starving Cells to Feeding}

When starving cells are fed, their $\mathrm{O}_{2}$-consumption increases measurably within a few minutes. The time taken for the respiratory rate to reach the level characteristic for cells during balanced, exponential growth at the given food concentration depends on the length of the starvation period (Fig. 3). After 25 h starvation,

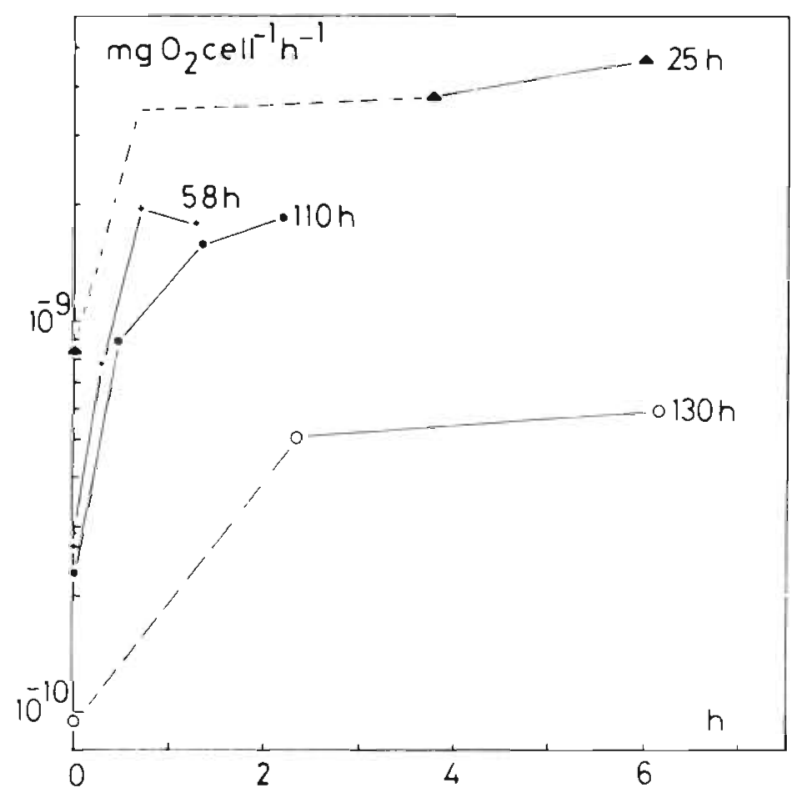

Fig. 3. Ochromonas sp. Rate of $\mathrm{O}_{2}$-uptake of cells starved for different periods of time and after feeding with approx. $2 \times 10^{8}$ bacteria $\mathrm{ml}^{-1}$

the level is reached after a few hours; after $130 \mathrm{~h}$ of starvation, $\mathrm{O}_{2}$-uptake is still only some $10 \%$ of the growth level after $6 \mathrm{~h}$ of feeding. The data suggest that after a long starvation period respiratory rate may increase in steps.

The ability to resume growth after starvation was tested by adding inoculates of starving cells to bacterial suspensions $(10$ and $20 \mathrm{~h}$ after the last cell division in a batch culture; thereafter for about every $24 \mathrm{~h}$ for the following $200 \mathrm{~h}$; see Fig. 4). Irrespective of the duration of starvation, cells immediately increased in volume when exposed to food bacteria. This increase was initially consistent with the expected uptake rate of bacteria at the offered concentration $\left(1.8 \times 10^{8}\right.$ $\mathrm{ml}^{-1}$ ): $170 \mathrm{~h}^{-1}$ and a volume of $0.6 \mu \mathrm{m}^{3}$ (Fenchel, 1982b). After cell divisions started, however, cell volume increased only slowly so that after long starvation 


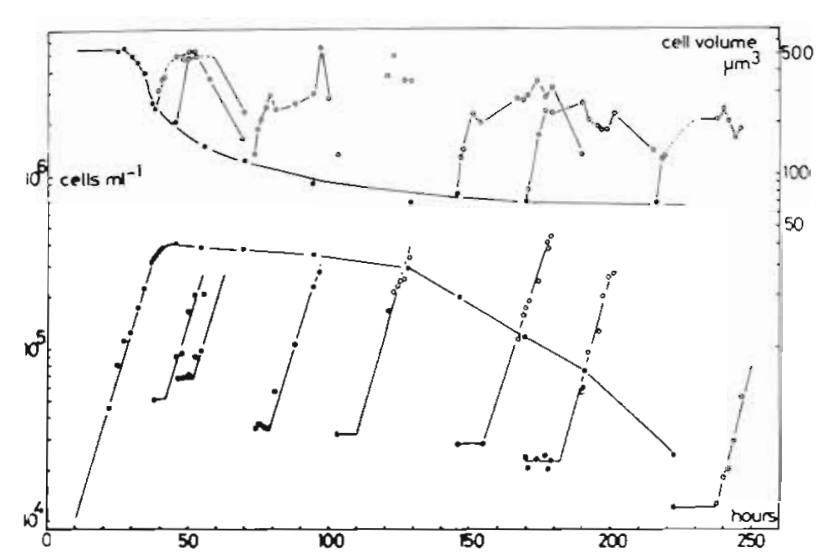

Fig. 4. Ochromonas sp. Numbers and volume of batch culture initiated with $2 \times 10^{8}$ bacteria $\mathrm{ml}^{-1}$. Also shown is growth and volume of sub-samples taken at different times during starvation and inoculated in bacterial suspensions

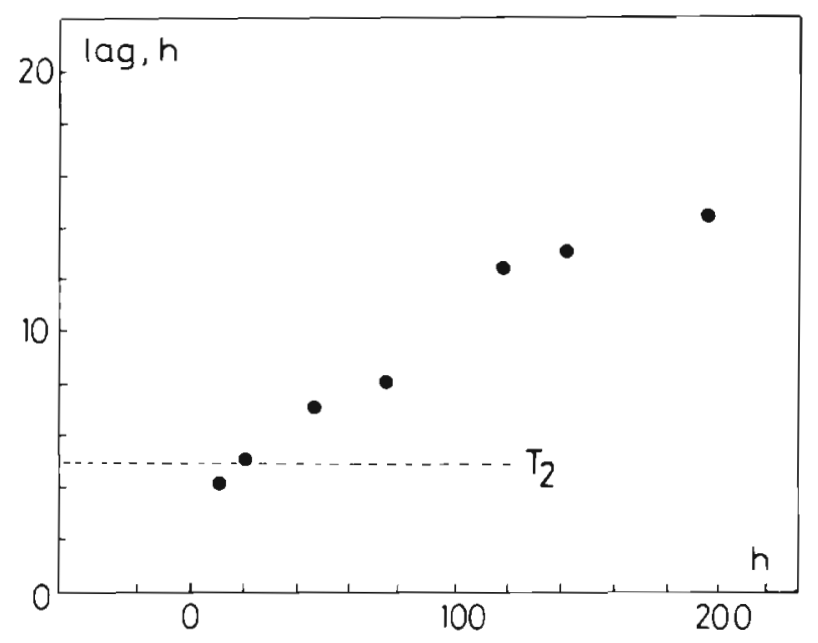

Fig. 5. Ochromonas sp. Data from Fig. 4 showing lag time as function of duration of starvation

periods, balanced growth was not achieved for several generations. Lag time was defined from the extrapolation of the exponential growth curve back to the initial cell number of the inoculate. Cells starved for only $10 \mathrm{~h}$ had a lag time of about $4 h_{\text {; }}$ after $20 \mathrm{~h}$ starvation, it equalled about 1 generation time $(5 \mathrm{~h})$; lag time increased further as a function of the duration of starvation to reach $15.5 \mathrm{~h}$ after $200 \mathrm{~h}$.

\section{Changes in Cell Morphology During Starvation}

Samples of cells were taken from a batch culture and fixed for TEM during late exponential growth and thereafter at intervals for $140 \mathrm{~h}$ (Fig. 6). Some examples are shown in Figs. 7 and $8 \mathrm{a}, \mathrm{b}$. In exponentially growing cells many ribosomes are arranged on the

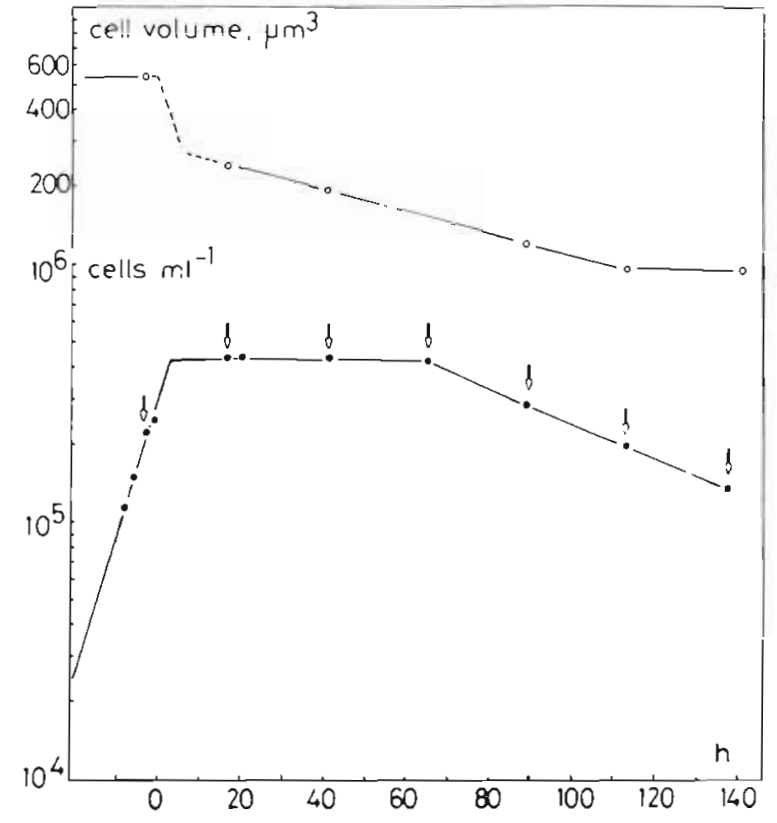

Fig. 6. Ochromonas sp. Development of batch culture sampled for TEM preparations at different times (arrows)

membranes of the endoplasmatic reticulum; immediately after the cessation of growth they become disorganized (Fig. 8a, b). Growing cells are also characterized by vacuoles with food bacteria and by the large, posterior vacuole, filled with myelin-like structures - likely to represent undigestable (lipid) remains of bacteria (Fig. $7 \mathrm{a}$ ). Cells fixed after $18 \mathrm{~h}$ were characterized by a large number of dividing mitochondria (Fig. 7b). Cells with a longer history of starvation showed a number of other changes. Mitochondria became fewer and smaller and many autophagous vacuoles appeared; these mainly contained degrading mitochondria, but also undifferentiated cytoplasm. Electron dense bodies, presumably lipid remains of otherwise digested organelles, accumulated (Fig. $7 \mathrm{C}$ ). Cells appeared increasingly vacuolated and after $100 \mathrm{~h}$ starvation little remained but the nucleus, a few mitochondria and the flagella with the associated microtubule systems (Fig. $7 \mathrm{~d}$ ).

As discussed in Fenchel (1982a), the studied Ochromonas sp. possess a chloroplast inside the nuclear membrane. In growing cells (in the dark or in the light) this remains very small (Figs, 7b, 8a) and cannot play any energetic role as growth rate does not increase in the light. Only during starvation in the light does the chloroplast grow to some prominence (Fig. 8c), but growth does not take place unless bacteria are supplied. Long time survival during starvation in the light was not studied.

A quantitative analysis of the micrographs con- 



Fig. 7. Ochromonas sp. TEM micrographs (a) Exponential growth; (b, c, d) starved for 18,66 and 140 h respectively. Scale: $1 \mu \mathrm{m}$. In (b), note dividing mitochondria (arrows); in (c) and (d), note autophagous vacuoles (arrows); in (c) they contain mitochondria 


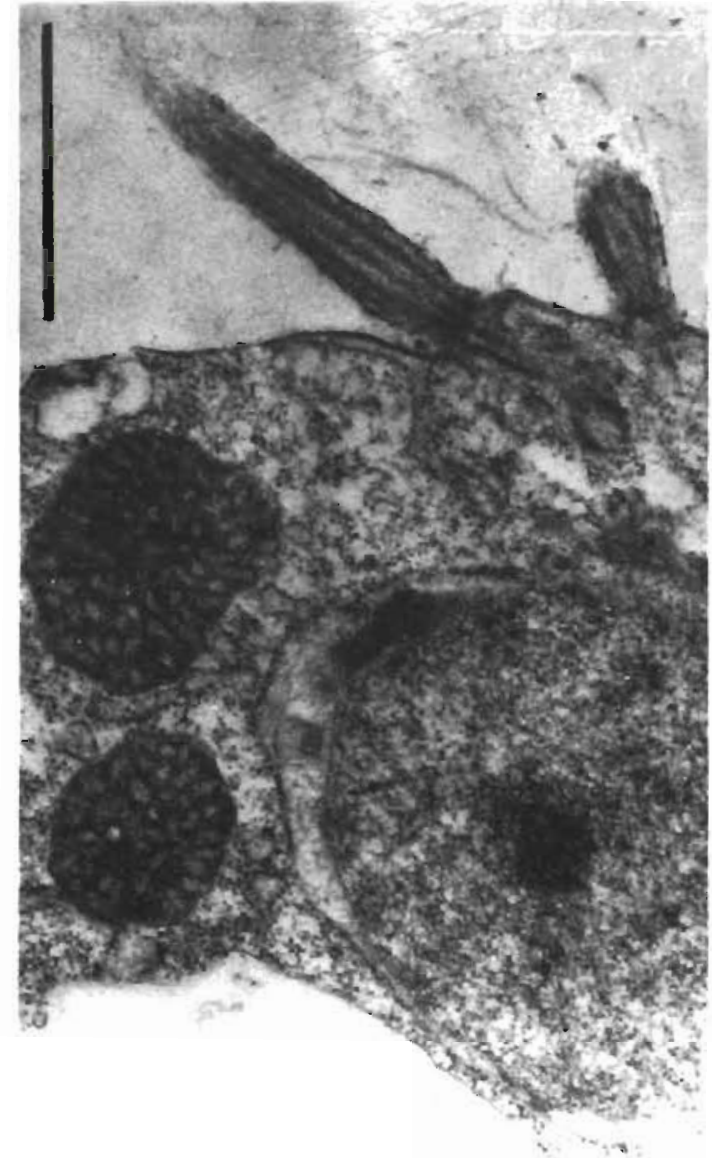

a
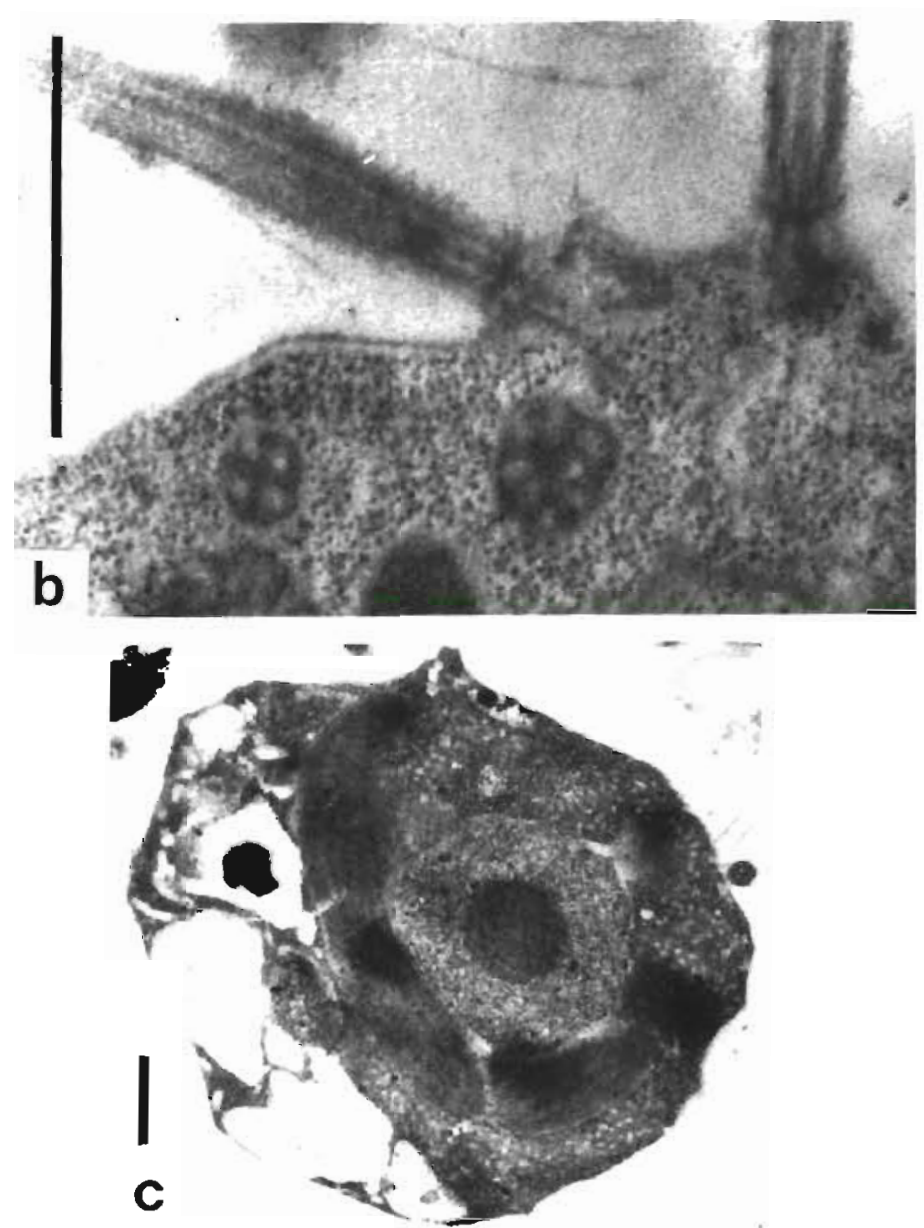

Fig. 8. Ochromonas sp. TEM micrographs. $(a, b)$ Cells sectioned through anterior flagellar area during exponential growth and after $18 \mathrm{~h}$ starvation respectively; (c) cell starved for $72 \mathrm{~h}$ in the light. Scale: $1 \mu \mathrm{m}$

firmed that, in particular, mitochondria undergo changes during starvation. Total mitochondrial volume per cell started to decrease immediately after the initiation of the starvation period and reached about $10 \%$ of that of growing cells in $80 \mathrm{~h}$ (Fig. 9). Fig. 10 shows some more details. The number of mitochondria nearly doubles shortly after the last cell division and simultaneously the individual volume of mitochondria decreases by a factor of two. Thereafter mitochondrial volume only decreases slowly but their numbers decrease by a factor of three during 80 to $90 \mathrm{~h}$. The internal surface of the tubular cristae per unit mitochondrial volume did not show any significant changes during the experiment. The nucleus as well as the nucleolus decreased in volume during starvation, the former by a factor of 5 and the latter by a factor of 10 (Fig. 11).

As a crude test of the reliability of the calculations and for comparison with the $\mathrm{O}_{2}$-uptake during the starvation, the loss of organic material was estimated from total cell volume minus the volume of vacuoles forming during starvation (measured as area fractions in the micrographs). From previous measurements (Fenchel, 1982b) it is known that $1 \mathrm{ml}$ Ochromonas sp. corresponds to about $80 \mathrm{mg} \mathrm{C}$. Fig. 12 shows the estimated loss of cellular carbon and the $\mathrm{O}_{2}$-uptake during starvation. Assuming a respiratory quotient of about unity, the results are not inconsistent.

\section{DISCUSSION AND CONCLUSIONS}

When evaluating the starvation experiments, the exact conditions prevailing in the cultures during the so-called stationary phase must be discussed with respect to the degree of absolute starvation. There are 2 mechanisms which may be considered. One is recycling of undigested material. As shown in Fenchel (1982b), only some $60 \%$ of the food bacteria are assimilated; the remaining organic $C$ might be recy- 


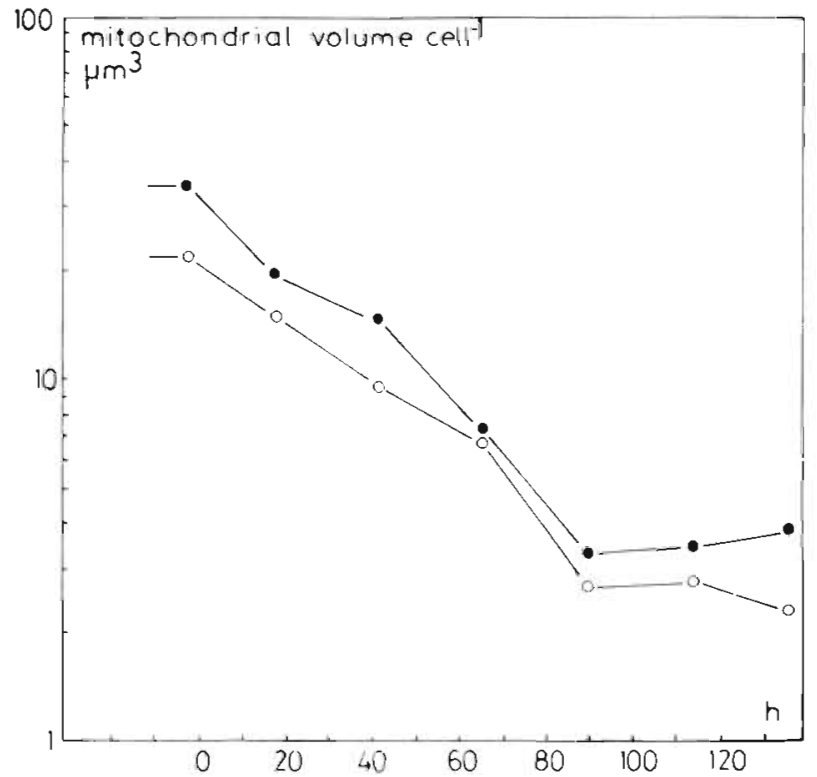

Fig. 9. Ochromonas sp. Mitochondrial volume per cell as function of time after termination of exponential growth phase. Filled circles: estimates based on area fraction; open circles: estimates based on numbers and dimensions of individual mitochondria

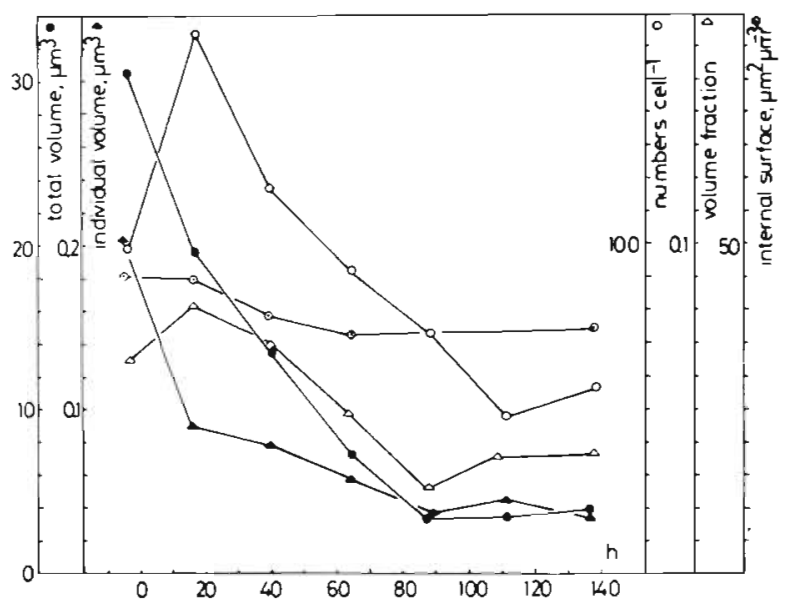

Fig. 10. Ochromonas sp. Total numbers, total volume, volume fraction, individual volume and internal surface of mitochondria as function of time after termination of exponential growth phase

cled by bacteria which could serve as food for the flagellates. However, bacteria were hardly observed (fluorescence microscopy) during the first ca. $100 \mathrm{~h}$ of starvation. Furthermore, the amount of egested material is relatively small as compared to the number of flagellates and the duration of the starvation period. After about $100 \mathrm{~h}$, mortality among the flagellates becomes evident and it is possible that these are partly recycled; also after this time some bacteria were

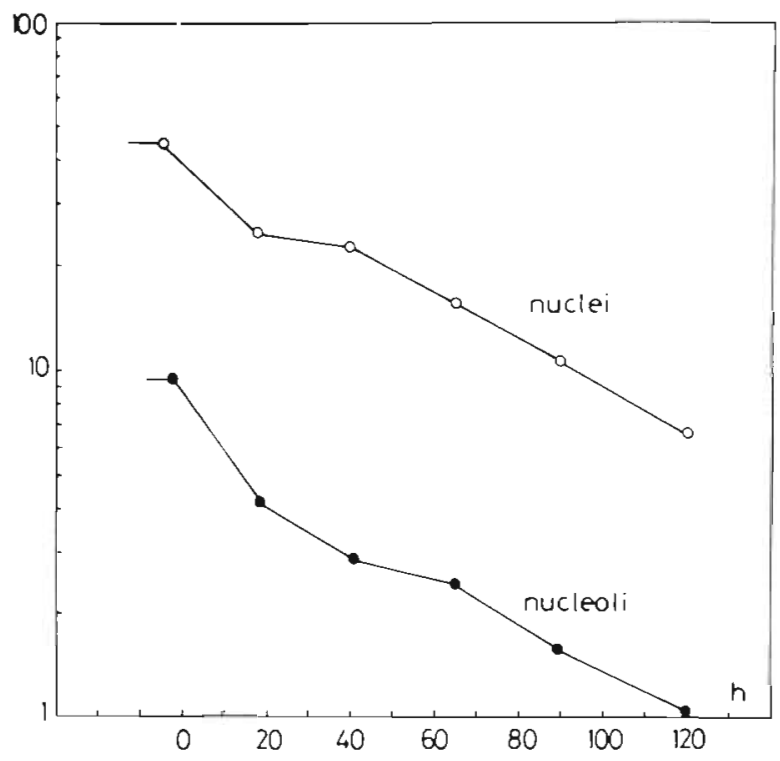

Fig. 11. Ochromonas sp. Volume of nuclei and nucleoli per cell as function of time after termination of exponential growth

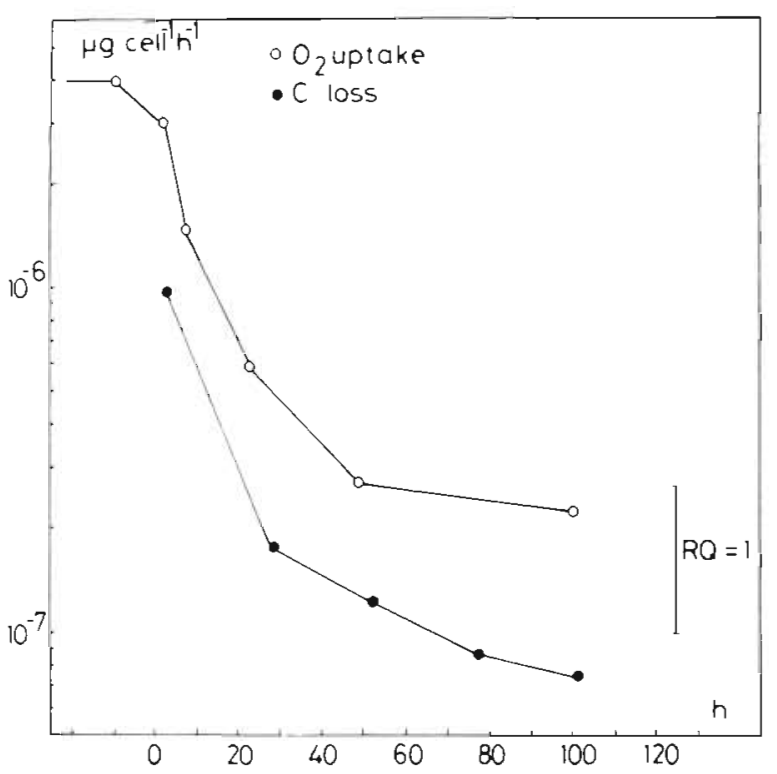

Fig. 12. Ochromonas sp. $\mathrm{O}_{2}$-uptake and $\mathrm{C}$-contents of cells during exponential growth and after different duration of starvation

observed in the cultures. In one experiment a culture was left for three months in the dark. At this time it was still possible to culture Ochromonas sp. from $1 \mathrm{ml} \mathrm{sam-}$ ples withdrawn from the flask, showing that after a long time a few cells may persist on the basis of a slow recycling of egested bacterial remains and dead flagellates. Another possibility to consider is cannibalism which is known in Ochromonas sp. (Schuster et al., 1968). Cannibalism in protozoans is often 
anthropomorphistically interpreted as a response to starvation; it is, of course, only a function of the probability of collision between 2 cells (that is of cell density which is highest at the end of the growth phase) and of the probability of a successful ingestion during encounter. In the present study, cannibalism was observed a few times at very high cell densities (around $10^{5} \mathrm{ml}^{-1}$ ), but cannot have played a significant role at the employed densities. Altogether, there is little evidence to support the possibility that the stable cell numbers during starvation represented cryptic growth since variation in cell size was small and since dividing cells were not observed.

With respect to the stereological methods, the estimation of area fractions and hence volume fractions is statistically very robust and variation in the results must be biological. The calculation of absolute volume (e.g. of mitochondria) depends, of course, on the estimate of total cell volume (based on light microscopy), on possible changes in dimensions during fixation and embedding of material for TEM, and on the accuracy of the stated magnification of the electron microscope. These sources of error were not evaluated, but it is reasonable to assume that they would not affect the relative comparisons between samples. The estimation of mitochondrial numbers is more open to discussion and less so to statistical analysis. When very oblong mitochondria with constrictions were excluded from the analysis, a close fit to cylindrical shape was found for the ellipsoidal cross sections. No branching of mitochondria was observed. The simplest assumption is therefore that the mitochondria normally are cylindrical, but that they become flattened prior to division (explaining the excess of oblong sections) and then divide longitudinally. The relatively good agreement between total mitochondrial volume estimated from individual dimensions with that estimated from area fractions support the interpretation, but a robust statistical analysis cannot be carried out.

There exist some previous, qualitative studies on fine structural changes in eukaryotic microorganisms during starvation (Trinci and Thurston, 1976) including the culiate Tetrahymena (Levy and Elliot, 1968; Nilsson, 1970) and Ochromonas (Schuster et al., 1968). These studies also showed autophagy of mitochondria and also of RNA derived from the nucleus and the permanent or transitory accumulation of lipids deriving from partly digested organelles. There is also some previous evidence of a rapid decrease in respiratory rate of protozoans exposed to starvation; Hamburger and Zeuthen (1971) found that Tetrahymena pyriformis decreased $\mathrm{O}_{2}$-uptake to about $30 \%$ of that of growing cells, but these authors did not follow the starving cells for a very long period.

It is likely that the observed changes are adaptive.
Clearly, if cells growing with a generation time of, say $4 \mathrm{~h}$ and with a net growth efficiency of $60 \%$ (Fenchel, $1982 \mathrm{~b}$ ), were to be exposed to absolute starvation, they would metabolize their entire cell $\mathrm{C}$ during 6 to $7 \mathrm{~h}$ if respiration remained unchanged. Consequently, the cells decrease their $\mathrm{O}_{2}$-uptake immediately as a response to decreased food intake.

This reflects rapid and fundamental changes in cell physiology. These include a reduction in protein synthesis and the reduction of respiratory potential through the autophagy of mitochondria. However, it is likely that the respiratory potential remains higher than the realized respiration. The mitochondrial volume decreases slower than actual $\mathrm{O}_{2}$-uptake and when starved cells are fed they show an immediate increase in respiratory rate.

The additional 1 or 2 cell divisions following the onset of starvation may also be considered adaptive. It is possible that the first division is due to processes in the cell cycle which once initiated continue to some point irrespective of environmental changes. However, in most eukaryote Protista starvation tends to block the cell cycle before division (Trinci and Thurston, 1976) so this would not account for a doubling of the entire population. Two successive divisions as found in Monosiga sp. and Pseudobodo tremulans can only be interpreted as an adaptation to adverse conditions. If, during starvation, the survival probability of the swarmers is only slightly higher than one fourth of that of a non-dividing parental cell, then fitness must be increased by these divisions.

It may seem strange, that in none of the clonal cultures of the 6 species studied (Fenchel, 1982a, b), was cyst formation observed as response to starvation. Chrysomonads are known to produce characteristic silicious cysts (Bourrelly, 1963) and cysts of choanoflagellates and of other microflagellates occur in marine plankton (Booth et al., 1980; Silver et al., 1980). Also, during the present study, cysts of chrysomonads and choanoflagellates were observed in older enrichment cultures based on seawater samples. Corliss and Esser (1974), reviewing cyst formation in protozoans, point to starvation as a factor which often induces encystment.

For a protozoan faced with starvation there are 2 properties which determine fitness. One, already discussed, is the maximization of survival. The other is the ability to resume growth rapidly again once food is available. As shown, a long period of starvation leads to a long lag time since the whole machinery of protein synthesis and of metabolism must be rebuilt before multiplication can proceed. The behaviour of a species during starvation is therefore a compromise between a low metabolic rate (long survival) and the ability to grow rapidly once food is available. The exact balance 
between these 2 fitness components must be determined by the selective regime, viz., the expected duration of starvation periods. It may therefore be speculated that cyst formation, while leading to a very low metabolic rate and hence a high probability of survival, also implies a long lag time once food becomes available. The clonal cultures employed in the present study were obtained from enrichment cultures through repeated initiations of dilution cultures. In this way, the populations were effectively forced through several cycles of feast and famine each lasting 4 to $7 \mathrm{~d}$ and this may have resulted in an efficient selection against cyst forming species or clonal lines originally present in the water sample.

Acknowledgements. I am grateful to Ms. Annie Selling for assistance with electron microscopical and other laboratory work and to Dr. F. B. Christiansen for discussions on statistical problems of stereology. The study was in part supported by Grant no 11-0949 from the Danish Natural Research Council.

\section{LITERATURE CITED}

Booth, B. C., Lewin, J., Norris, R. E. (1980). Siliceous nanoplankton. I. Newly discovered cysts from the Gulf of Alaska. Mar. Biol. 58: 205-209

Bourrelly, P. (1963). Loricae and cysts in the Chrysophyceae. Ann. N.Y. Acad. Sci. 108: 421-429

Corliss, J. O., Esser, S. C. (1974). Comments on the role of the cyst in the life cycle and survival of free-living protozoa. Trans. Am. micros. Soc. 93: 578-593

Curds, C. R., Cockburn, A. (1968). Studies on the growth and feeding of Tetrahymena pyriformis in axenic and monoxenic culture. J. gen. Microbiol. 54: 343-358

Curds, C. R., Cockburn, A. (1971). Continuous monoxenic culture of Tetrahymena pyriformis. J. gen. Microbiol. 66 $95-108$

Elias, H., Hennig, A., Schwarz, D. E. (1968). Stereology: Applications to biomedical research. Physiol. Rev. 51 : 158-200

Fenchel, T. (1982a). Ecology of heterotrophic microflagellates. I. Some important forms and their functional morphology. Mar Ecol. Prog. Ser 8: 211-223

Fenchel, T. (1982b). Ecology of heterotrophic microflagellates. II. Bioenergetics and growth. Mar. Ecol. Prog. Ser. 8: $225-231$
Fenchel, T (1982c). Ecology of heterotrophic microflagellates. IV. Quantitative occurrence and importance as bacterial consumers. Mar Ecol. Prog. Ser. 9: 35-42

Finlay, B. J. (1978). Community production and respiration by ciliated protozoa in the benthos of a small eutrophic loch. Freshwater Biol. 8: 327-341

Hamburger, K., Zeuthen, E. (1971). Respiratory responses to dissolved food of starved, normal and divisionsynchronized Tetrahymena cells. C. r. Trav. Lab. Carisberg 38: 145-161

Hamilton, R. D., Preslan, J. E. (1970). Observations on the continuous culture of a planktonic phagotrophic protozoan. J. exp. mar. Biol. Ecol. 5: 94-104

Haury, L. R., McGowan, J. A., Wiebe, P. H. (1978). Patterns and processes of plankton distributions. In: Steele, J. $\mathrm{H}$. (ed.) Spatial pattern in plankton communities. Plenum Press, New York, pp. 277-327

Hennig, A. (1967). Fehlerbetrachtungen zur Volumenbestimmung aus der Integration ebener Schnitte. In: Weibel, E. R., Elias, H. (eds.) Quantitative methods in morphology, Springer, Berlin, pp. 99-129

Koch, A. L. (1971). The adaptive responses of Escherichia coli to a feast and famine existence. Adv. microb. Physiol. 6: $147-217$

Laybourn, J. E. M., Finlay, B. J. (1976). Respiratory energy losses related to cell weight and temperature in ciliated protozoa. Oecologia (Berl.) 24: 349-355

Levy, M. R., Elliot, A. M. (1968). Biochemical and ultrastructural changes in Tetrahymena pyriformis during starvation. J. Protozool. 15: 208-222

Meyer-Reil, L.-A, Bölter, M., Liebezeit, G., Schramm, W. (1979). Short-term variations in microbiological and chemical parameters. Mar. Ecol. Prog. Ser. 1: 1-6

Nilsson, J. R. (1970). Cytolysomes in Tetrahymena pyriformis GL. C. I Trav. Lab. Carlsberg 38: 87-121

Schuster, F. L., Hershenov, B., Aaronson, S. (1968). Ultrastructural observations on aging of stationary cultures and feeding in Ochromonas. J. Protozool. 15: 335-346

Silver, M. W., Mitchell, J. G., Ringo, D. L. (1980). Silicious nanoplankton. II. Newly discovered cysts and abundant choanoflagellates from the Wedell Sea, Antarctica. Mar. Biol. 58: 211-217

Trinci, A. P. J., Thurston, C. F. (1976). Transition to the nongrowing state in eukaryotic micro-organisms. In: Gray, $T$. R. G., Postgate, J. R. (eds.). The survival of vegetative microbes. Cambridge University Press, Cambridge, pp. 55-79

Weibel, E. R., Elias, H. (1967). Introduction to stereologic principles. In: Weibel, E. R., Elias, H. (eds.) Quantitative methods in morphology. Springer, Berlin, pp. 89-98 